\section{9 update: EULAR RA management recommendations, efficacy and safety systematic literature reviews}

\author{
Peter Nash
}

\begin{abstract}
'The main aim of evidence-based treatment recommendations and guidelines are to translate findings from health research into clinical practice. When implemented successfully these should improve quality of care and lead to improved health outcomes. $^{1}$
\end{abstract}

This issue of the journal contains the latest update of the European League Against Rheumatism, Rheumatoid Arthrits (EULAR RA) management recommendations as well as the efficacy and safety systematic literature reviews representing an enormous amount of work by a dedicated team. As we enter a new decade, it is timely to consider the utility and worth of this extensive endeavour.

RA management guidelines have been popular for the last two and a half decades and have recently undergone metaanalysis. $^{2}$ EULAR committee defined in 2004 the standard operating procedures required to tackle such a task. ${ }^{3}$

A number of aspects need highlighting.

These are 'recommendations' and not 'guidelines'-the latter having medicolegal implications particularly as much of the advice is based on expert opinion in the absence of appropriate clinical trials and further the level of agreement while high is rarely unanimous. The delphi voting process on principles and recommendations allocates $>75 \%$ as a majority and lesser percentages for second and third rounds of voting.

As newer clinical trials are presented and published, and as questions highlighted in the research agenda are answered, the recommendations require updating every few years to stay current and not be out of date as soon as published. For this reason, a cut-off date is applied and evidence from registries and abstracts and presentations of phase III clinical trials at meetings before being published in peer-reviewed

School of Medicine, Griffith University, Brisbane, QLD, Australia

Correspondence to Professor Peter Nash, School of Medicine, Griffith University, Brisbane, QLD 9726, Australia; drpnash@tpg.com.au journals are accepted in the systematic literature review.

An experienced steering committee shepherds the process through to a task force that includes rheumatologists from across the Globe, patient partners and other subspecialists as required, for example, infectious disease physicians, haematologists and so on. Subgroups analyse specific topics followed by a group delphi voting process where recommendations and in particular their wording are critically examined. Further, prior recommendations have a published patient version. ${ }^{4}$

The authors are cogniscent of therapeutic issues in economically challenged countries, so the recommendations have strived to be practical although aspirational, that is, externally valid, applicable to patients in routine care and addressing clinically relevant questions while defining best practice. Rather than divide patients into undifferentiated or early or established disease which are covered in other EULAR recommendations, patients are analysed as conventional synthetic disease modifying anti-rheumatic drug (csDMARD) naive, csDMARD inadequate responders and biologic DMARD (bDMARD)/targeted synthetic DMARD (tsDMARD) inadequate responders.

The recommendations lend themselves for use by national associations to argue with regulators and reimbursers to make therapy more accessible by defining evidence based standard of care. Further, therapies not approved in Europe are included to pre-empt their approval and add universality.

It is important to be aware of the detailed explanations in the systematic reviews referred to as caveats in the recommendations.

Can the impact of prior recommendations be assessed and their impact on outcome measured? While many studies have analysed 'treat to target' adherence, recommendation adherence is less well studied. Yates et $a l^{5}$ examined this question in 7154 patients with RA from 134 rheumatology departments and found broad variance, good low dose corticosteroid adherence and substantial deviation from guidelines. Further studies are needed.

So what are the major differences from the previous update given new evidence to support or contradict the recommendations, the introduction of novel therapies and new strategic insights?

While the principles are 'common sense' rather than evidence-based, a fifth overarching principle was added that patients are likely to require multiple successive therapies throughout life and highlighted the requirement for access to multiple therapies with differing methods of action.

Nine of 12 recommendations were unchanged.

Recommendation 8 revised the preference of bDMARDs over tsDMARDs to make them equal alternates and the wording from 'considered' to 'added' in the setting of poor prognostic factors and treatment target not achieved.

Recommendation 10 placed agents with another mechanism of action ahead of a second TNFi.

Recommendation 11 added tsDMARDs to a tapering strategy.

There was less discussion over the role of bridging corticosteroids and importance of methotrexate therapy.

The treat-to-target principle of early remission induction with corticosteroids and csDMARD was reinforced and the combination of csDMARDS with bDMARDS and tsDMARDS reiterated.

A note of caution was added about searching for ever subtle improvements in efficacy and safety and the perils of overdiagnosis and overtreatment.

The research agenda was updated.

In conclusion, given the high citation rates of the Eular RA management recommendations and their popularity including from other Specialties, this update has achieved a therapeutic maturity supported in the main by the available evidence so that as Churchill once observed as far as managing Rheumatoid Arthritis is concerned and while battling for a cure:

'Now this is not the end. It is not even the beginning of the end. But it is, perhaps, the end of the beginning.'

Correction notice This article has been corrected since it published Online First. Reference one has been corrected.

Handling editor Dimitrios T Boumpas

Funding The authors have not declared a specific grant for this research from any funding agency in the public, commercial or not-for-profit sectors.

Competing interests None declared.

Patient consent for publication Not required. 
Provenance and peer review Commissioned; internally peer reviewed.

- https://doi.org/10.1136/annrheumdis-2019-216655

- https://doi.org/10.1136/annrheumdis-2019-216656

(C) Author(s) (or their employer(s)) 2020. No commercial re-use. See rights and permissions. Published by BMJ.

\section{(D) Check for updates}

To cite Nash P. Ann Rheum Dis 2020;79:679-680.

Received 27 January 2020

Accepted 28 January 2020

Published Online First 7 February 2020

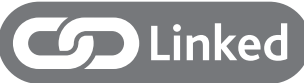

https://doi.org/10.1136/annrheumdis-2019-216653
Ann Rheum Dis 2020;79:679-680.

doi:10.1136/annrheumdis-2019-216821

\section{ORCID iD}

Peter Nash http://orcid.org/0000-0002-2571-788X

\section{REFERENCES}

1 Buchbinder R. SP0206 Generalising from clinical 2014;73:53.3-53.

2 Mian A, Ibrahim F, Scott DL. A systematic review of guidelines for managing rheumatoid arthritis. BMC Rheumatol 2019;3.

3 Dougados M, Betteridge N, Burmeister G. EULAR standardised operating procedures for trials to treatment recommendations. Ann Rheum Dis the elaboration, evaluation, dissemination, and implementation of recommendations endorsed by the EULAR standing committees. Ann Rheum Dis 2004;63:1172-6.

4 de Wit MPT, Smolen JS, Gossec L, et al. Treating rheumatoid arthritis to target: the patient version of the international recommendations. Ann Rheum Dis 2011;70:891-5.

5 Yates M, MacGregor AJ, Ledingham J, et al. Variation and implications of treatment decisions in early rheumatoid arthritis: results from a nationwide cohort study. Rheumatology 2019;364.

6 Smolen JS, Landewé RBM, Bijlsma JWJ, et al. EULAR recommendations for the management of rheumatoid arthritis with synthetic and biological disease-modifying antirheumatic drugs: 2019 update. Ann Rheum Dis 2020;79:684-98. 